\title{
Determinants of the growth hormone nadir during oral glucose tolerance test in adults
}

\author{
Phillip J Monaghan ${ }^{1}$ and Peter J Trainer ${ }^{2}$ \\ 'Department of Clinical Biochemistry, The Christie Pathology Partnership, The Christie NHS Foundation Trust; \\ University of Manchester, Faculty of Medical and Human Sciences, Institute of Inflammation and Repair, Manchester, \\ UK and ${ }^{2}$ Department of Endocrinology, The Christie NHS Foundation Trust; University of Manchester, Manchester \\ Academic Health Science Centre, Manchester, UK
}

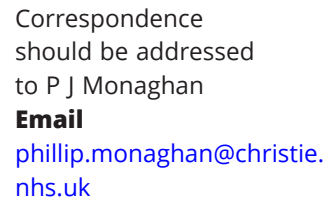

Synergy between clinician and laboratory is fundamental to delivering best care. Endocrinologists rely on hormone measurement for diagnosis and to judge the effectiveness of every therapeutic intervention, which places upon them an obligation to understand the characteristics and limitations of the assays being undertaken in their name; none more so than for biochemical assessment of the growth axis. The phenotypic and metabolic consequences of GH excess develop insidiously and all too frequently symptoms are present for several years before acromegaly is considered. In most patients, once suspected, the diagnosis is rapidly confirmed by unequivocally elevated GH and IGF-I concentrations. The challenge is to diagnose acromegaly earlier in its natural history when the damage done is hopefully still reversible, but by definition the phenotype and biochemical disturbance will be more subtle. Prior to the availability of effective surgical and pharmacological treatment, discussion on the definition of disease control was largely academic, but with evermore effective treatment it is important to have evidence-based biochemical criteria for success.

The last two decades have witnessed intense debate concerning the cut-offs for the diagnosis of acromegaly and definition of disease control for therapeutics goals (1). In 2000, the 'Criteria for Cure of Acromegaly: A Consensus Statement' proposed that 'GH suppression after an oral glucose load to $1 \mu \mathrm{g} / \mathrm{L}$ or less excluded the diagnosis of acromegaly', and, in the treated patient, was indicative of disease control (2). The validity of the $1 \mu \mathrm{g} / \mathrm{L}$ cut-off has been questioned by studies reporting suppression of $\mathrm{GH}$ to $<1 \mu \mathrm{g} / \mathrm{L}$ in response to glucose in newly diagnosed acromegaly (3) and in judging the outcome of transsphenoidal surgery. Freda et al. (4) used highly sensitive, monoclonal IRMA or ultrasensitive ELISA GH assays to evaluate 60 post-transsphenoidal patients and found that in 50\% of patients (11 of 22 ) with active disease (defined by elevated IGF-I) GH suppressed to $<1 \mu \mathrm{g} / \mathrm{L}$, while in their longitudinal follow-up study, 5 of $19(26 \%)$ patients in initial remission (normal IGF-1 and GH nadir $<1 \mu \mathrm{g} / \mathrm{L}$ ) relapsed (elevated IGF-1) during follow-up, all of whom had a GH nadir when originally studied in the range $0.14-1 \mu \mathrm{g} / \mathrm{L}$. None of the 30 patients with a nadir $<0.14 \mu \mathrm{g} / \mathrm{L}$ relapsed (5).

In light of these and other studies, it came as a surprise that in 2014, the Endocrine Society Clinical Practice Guideline promulgated the same $1 \mu \mathrm{g} / \mathrm{L}$ criterion for the diagnosis of acromegaly, also stating that a postoperative 'serum GH $<0.14 \mu \mathrm{g} / \mathrm{L}$ suggests surgical remission', qualified by the seemingly contradictory remark that 'many assays do not have sufficient accuracy at GH levels $<1 \mu \mathrm{g} / \mathrm{L}^{\prime}$ (6). Ultrasensitive assays have been widely used for research for two decades, for example Freda et al. used ELISA with reported analytical sensitivity of $0.01 \mu \mathrm{g} / \mathrm{L}$, indicating the requisite precision below $1 \mu \mathrm{g} / \mathrm{L}$ for diagnosis and postoperative follow-up, to be eminently achievable. In fact, many modern commercially available GH immunoassays are now equipped with equivalent analytical sensitivity and adequate analytical range for use in acromegaly. These include Siemens (Immulite): measurement range $0.05-40 \mu \mathrm{g} / \mathrm{L}$, Beckman (Access): 0.002-35 $\mu \mathrm{g} / \mathrm{L}$, DiaSorin (Liaison): 0.05-80 $\mu \mathrm{g} / \mathrm{L}$, Roche (Cobas): $0.03-50 \mu \mathrm{g} / \mathrm{L}$, IDS (iSYS): $0.05-100 \mu \mathrm{g} / \mathrm{L}$; the five main suppliers based on recent data from the UK National External Quality Assessment Service (UK NEQAS). Between-assay bias however remains a critical hindrance to the adoption of consensus guidelines, as illustrated by a comparison of three, then popular, commercial assays that demonstrated a six-fold discrepancy between the Siemens Immulite 2000 and the DSL ELISA for postglucose GH nadir in 46 patients with acromegaly (7).

Published by Bioscientifica Ltd. 
Indeed, UK NEQAS data reveal for a specimen close to the $1 \mu \mathrm{g} / \mathrm{L}$ cut-off, coefficient of variation $(\mathrm{CV})$ remains well above $10 \%$ when taking into account GH results submitted by all participating laboratories, encompassing all the various assay methodologies currently in use, whereas the equivalent picture for laboratories using the same analyser is somewhat more impressive with $\mathrm{CV}$ of approximately $5 \%$. The emphasis within guidelines on assay performance is to be welcomed but highlights the challenge of applying international consensus criteria to local practice.

The good news is that in parallel to discussions of cutoff criteria, there have been incremental improvements in the accuracy and ease by which serum GH is measured. The combination of shorter assay incubation times (enabling improved turnaround times) and the ousting of conventional radio-isotopic labels for modern chemiluminescence technology - which is readily amenable to assay automation, have greatly simplified laboratory workflow. The transition from polyclonal reagent antibodies that detected multiple GH isoforms, to monoclonal antibodies specific for the $22 \mathrm{kDa}$ isoform, combined with the widespread adoption of recombinant International Standard IS $98 / 574$ containing $22 \mathrm{kDa}$ GH of $>95 \%$ purity has assisted with assay harmonisation and attempts to minimise between-assay bias. A logical consequence of embracing IS $98 / 574$ as the single calibrant for $\mathrm{GH}$ measurement was consistency of reporting results in mass units $(\mu \mathrm{g} / \mathrm{L})$, eliminating the use of variable conversion factors between $\mathrm{mU} / \mathrm{L}$ and $\mu \mathrm{g} / \mathrm{L}$ (8). All the same, numerous challenges still pervade assay performance, including (1) assay traceability - linking results from a patient sample to a commonly accepted reference, making results comparable across measurement systems, location and time and (2) commutability simply stated, ensuring the equivalence of the results for a reference material and patient samples, that is, the elimination of matrix effect. Commutability gaps in the traceability chain of GH assays have been identified, dependent on both reconstitution protocol and background matrix, with recommendations to alleviate these issues including the production of commutable matrix reference material for use in the preparation of method calibrants (9). Further improvement in this area can be anticipated, as the diagnostics industry transition to new EU regulation (EU In Vitro Diagnostic Regulation; 2017/746) (10).

The most recent consensus statement (2018) on acromegaly outcomes, acknowledged the progress and the availability of sensitive GH assays and recommended an OGTT nadir serum GH cut-off $<0.4 \mu \mathrm{g} / \mathrm{L}$ (11), reflecting the emergence of commercial assays with improved sensitivity and specificity that not only enable the GH cut-off criteria in patients with acromegaly to be lowered but also permit the establishment of normative data derived from studies in healthy subjects. The gold standard for IGF-I reference intervals was established by Bidlingmaier and colleagues (12) who accessed 15,014 samples from 12 healthy subject cohort studies from six countries covering ages from 0 to 94 years to define the IGF-I reference intervals for the IDS iSYS immunometric assay methodology. The Bidlingmaier laboratory, using the iSYS platform, has global impact as the reference centre responsible for measurement of GH and IGF-I in many clinical trials of GH replacement therapy and pharmacological interventions for acromegaly. It is therefore to be welcomed that a Clinical Study published recently in the European Journal of Endocrinology, this group (Schilbach and colleagues) report GH nadir concentrations during an OGTT (measured on the iSYS platform) derived from 525 participants from 2 German and 1 Danish healthy subject cohort studies (13).

This automated GH assay is specific for the $22 \mathrm{kDa}$ GH isoform, with no interference from GHBP or the presence of pegvisomant. nor cross-reactivity with either placental GH or placental lactogen. In contrast to previous, largely 'for research use only' assays, there is good linearity and recovery, broad reportable range $(0.05-100 \mu \mathrm{g} / \mathrm{L})$, with a short run time at approximately $35 \mathrm{~min}$ to first result (with subsequent GH results released every $25 \mathrm{~s}$ ) and is calibrated to IS 98/574 reference preparation (14). The authors report a mean GH nadir in healthy subjects $(0.17 \mu \mathrm{g} / \mathrm{L}$, s.D. 0.33 , $n=525$ ) distinct from the proposed acromegaly cut-off criteria of $0.4 \mu \mathrm{g} / \mathrm{L}$. Consistent with previous studies of GH secretion, BMI (negatively correlation), sex (lower in men) and oestrogen status (higher on oral oestradiol) are major determinants of the GH nadir, although contrary to previous studies, age does not appear to have an impact $(4,15,16)$.

The authors elaborate on the biological variables which constitute the major determinants of GH nadir during OGTT and speculate that for daily clinical practice, two different nadir cut-offs are used; $0.4 \mu \mathrm{g} / \mathrm{L}$ in nonobese subjects (BMI $<25 \mathrm{~kg} / \mathrm{m}^{2}$ ) and $0.2 \mu \mathrm{g} / \mathrm{L}$ for those with a BMI $\geq 25 \mathrm{~kg} / \mathrm{m}^{2}$. However, we would argue that such a binary approach lacks biological logic. Without even considering sex and oestrogen status, is a man with a BMI of $24 \mathrm{~kg} / \mathrm{m}^{2}$ so different from one with a BMI of 
$25 \mathrm{~kg} / \mathrm{m}^{2}$ ? Besides, patients with acromegaly are heavy, have reduced fat mass and potentially loss of height (from vertebral body fracture), all of which limit the clinical utility of BMI as a measure of body composition in these patients.

To inform future consensus statements and to judge the value of the normative data reported herein, comparison is required with the results of OGTT undertaken in treated patients with acromegaly in whom the disease is, or is nearly, 'controlled'. In other words, for the studies previously undertaken by Freda and colleagues (as discussed above), to be repeated utilising this, and other, modern automated commercial GH assays.

Pending data from studies in patients with acromegaly, the Schilbach paper should encourage laboratories using this assay to report results down to the lower limit of quantification (LLoQ) rather than an arbitrary cut-off, and for endocrinologists to be receptive to the possibility that treated patients with nadir GH values $<0.4 \mu \mathrm{g} / \mathrm{L}$ may not be 'cured', as that cut-off is significantly higher than the mean in healthy subjects of $0.17 \mu \mathrm{g} / \mathrm{L}$, and require monitoring for evidence of recurrence. The stars are aligning with the availability of robust and sensitive automated GH immunoassay and now the availability of normative data, warranting a critical re-evaluation of the biochemical outcomes for acromegaly. This study sets the benchmark against which GH nadir for other commercial GH assays should be judged, while also highlighting areas for further assay refinement. $24 \%$ of GH nadir values were below the LLoQ, and in 35 subjects in whom IGF-1 was normal, the nadir was $\geq 0.4 \mu \mathrm{g} / \mathrm{L}$; in 5 cases $\geq 1 \mu \mathrm{g} / \mathrm{L}$, with the highest nadir being $5.46 \mu \mathrm{g} / \mathrm{L}$ (IGF-I $42 \%$ of ULN). The most intriguing subject had a GH nadir of $0.45 \mu \mathrm{g} / \mathrm{L}$ with an IGF-1 99\% of ULN, but alas we will never know if the participant had signs of an emerging acromegaly, which illustrates the undiminished importance, however good assays get, of clinicians continuing to talk to and examine their patients.

\section{Declaration of interest}

P J M declares that The Christie Pathology Partnership is the reference measurement centre for the UK National Acromegaly Register and that this institution has received financial support from Immunodiagnostic Systems PLC for performing external quality verification for IGF-I reagent.

\section{Funding}

This work did not receive any specific grant from any funding agency in the public, commercial, or not-for-profit sector.

\section{References}

1 Trainer PJ. Acromegaly-consensus, what consensus? Journal of Clinical Endocrinology and Metabolism 200287 3534-3536. (https:// doi.org/10.1210/jc.87.8.3534)

2 Giustina A, Barkan A, Casanueva FF, Cavagnini F, Frohman L, Ho K, Veldhuis J, Wass J, Von Werder K \& Melmed S. Criteria for cure of acromegaly: a consensus statement. Journal of Clinical Endocrinology and Metabolism 200085 526-529. (https://doi.org/10.1210/ jc.85.2.526)

3 Dimaraki EV, Jaffe CA, DeMott-Friberg R, Chandler WF \& Barkan AL. Acromegaly with apparently normal GH secretion: implications for diagnosis and follow-up. Journal of Clinical Endocrinology and Metabolism 200287 3537-3542. (https://doi.org/10.1210/ jcem.87.8.8658)

4 Freda PU, Post KD, Powell JS \& Wardlaw SL. Evaluation of disease status with sensitive measures of growth hormone secretion in 60 postoperative patients with acromegaly. Journal of Clinical Endocrinology and Metabolism 199883 3808-3816. (https://doi. org/10.1210/jcem.83.11.5266)

5 Freda PU, Nuruzzaman AT, Reyes CM, Sundeen RE \& Post KD. Significance of "abnormal" nadir growth hormone levels after oral glucose in postoperative patients with acromegaly in remission with normal insulin-like growth factor-I levels. Journal of Clinical Endocrinology and Metabolism 200489 495-500. (https://doi. org/10.1210/jc.2003-031316)

6 Katznelson L, Laws ER Jr, Melmed S, Molitch ME, Murad MH, Utz A, Wass JAH \& Endocrine Society. Acromegaly: an endocrine society clinical practice guideline. Journal of Clinical Endocrinology and Metabolism 201499 3933-3951. (https://doi.org/10.1210/jc.20142700)

7 Arafat AM, Möhlig M, Weickert MO, Perschel FH, Purschwitz J, Spranger J, Strasburger CJ, Schöfl C \& Pfeiffer AFH. Growth hormone response during oral glucose tolerance test: the impact of assay method on the estimation of reference values in patients with acromegaly and in healthy controls, and the role of gender, age, and body mass index. Journal of Clinical Endocrinology and Metabolism 200893 1254-1262. (https://doi.org/10.1210/jc.2007-2084)

8 Sheppard MC. Growth hormone assay standardization: an important clinical advance. Clinical Endocrinology 200766 157-161. (https:// doi.org/10.1111/j.1365-2265.2007.02703.x)

9 Boulo S, Hanisch K, Bidlingmaier M, Arsene C-G, Panteghini M, Auclair G, Sturgeon C, Schimmel H \& Zegers I. Gaps in the traceability chain of human growthhormone measurements. Clinical Chemistry 201359 1074-1082. (https://doi.org/10.1373/ clinchem.2012.199489)

10 Regulation (EU) 2017/746 of the European Parliament and of the Council of 5 April 2017. (available at: https://eur-lex.europa.eu/legalcontent/EN/TXT/PDF/?uri=CELEX:32017R0746\&from=EN). Accessed on 9 August 2019.

11 Melmed S, Bronstein MD, Chanson P, Klibanski A, Casanueva FF, Wass JAH, Strasburger CJ, Luger A, Clemmons DR \& Giustina A. A consensus statement on acromegaly therapeutic outcomes. Nature Reviews Endocrinology 201814 552-561. (https://doi.org/10.1038/ s41574-018-0058-5)

12 Bidlingmaier M, Friedrich N, Emeny RT, Spranger J, Wolthers OD, Roswall J, Körner A, Obermayer-Pietsch B, Hübener C, Dahlgren J et al. Reference intervals for insulin-like growth factor-1 (igf-i) from birth to senescence: results from a multicenter study using a new automated chemiluminescence IGF-I immunoassay conforming to recent international recommendations. Journal of Clinical Endocrinology and Metabolism 201499 1712-1721. (https:// doi.org/10.1210/jc.2013-3059)

13 Schilbach K, Gar C, Lechner A, Nicolay SS, Schwerdt L, Haenelt M, Dal J, Jørgensen J-OL, Störmann S, Schopohl J et al. Determinants 
of the growth hormone nadir during oral glucose tolerance test in adults. European Journal of Endocrinology 2019181 55-67. (https://doi. org/10.1530/EJE-19-0139)

14 Manolopoulou J, Alami Y, Petersenn S, Schopohl J, Wu Z,Strasburger CJ \& Bidlingmaier M. Automated 22-kD growth hormone-specific Assaywithout interference from pegvisomant. Clinical Chemistry 201258 1446-1456. (https://doi.org/10.1373/ clinchem.2012.188128)

15 Colao A, Pivonello R, Auriemma RS, Grasso LFS, Galdiero M, Pivonello C, Lombardi G \& Savastano S. Growth hormone nadir during oral glucose load depends on waist circumference, gender and age: normative data in 231 healthy subjects.

Clinical Endocrinology 201174 234-240. (https://doi.org/10.1111/ j.1365-2265.2010.03896.x)

16 Colao A, Pivonello R, Cavallo LM, Gaccione M, Auriemma RS, Esposito F, Cappabianca P \& Lombardi G. Age changes the diagnostic accuracy of mean profile and nadir growth hormone levels after oral glucose in postoperative patients with acromegaly. Clinical Endocrinology 200665 250-256. (https://doi.org/10.1111/j.13652265.2006.02584.x)

Received 20 August 2019

Accepted 2 September 2019 